\title{
Pressure Transducer with Au-Ni Thin-Film Strain Gauges
}

\author{
K. Rajanna, S. Mohan, M. M. Nayak, N. Gunasekaran, and A. E. Muthunayagam
}

\begin{abstract}
The behavior of a pressure transducer with $\mathrm{Au}-\mathrm{Ni}$ (89: 11) film as strain gauges have been studied. The effects of post-deposition heat treatment on the resistance of the thin-film strain gauges and hence the output performance of the pressure transducer are discussed. The effect of a repeated number of pressure cycles carried out over a period of eight months has also been reported. The maximum nonlinearity and the hysteresis is improved from $0.92 \%$ FSO to $0.06 \%$ FSO after 1000 pressure cycles. The output behavior of the pressure transducer with temperature has also been studied.
\end{abstract}

\section{INTRODUCTION}

$P$ RESSURE transducers are basically electromechanical devices used for a variety of applications. The primary function of the pressure transducer is to sense fluid pressure and provide an electrical output proportional to the input pressure. A pressure transducer essentially consists of a diaphragm which undergoes deformation due to applied pressure. This mechanical deformation of the diaphragm in converted into an electrical response by a strain gauge bonded to it. It was more common to use foil-type strain gauges for this purpose. However, in recent years, the use of thin-film strain gauges as sensors in pressure transducers has gained importance due to their numerous merits. The distinct advantages are absence of adhesive material, flexibility to tailor the properties of the sensing film, etc. Although several investigations on the strain sensitivity of different metal [1]-[16] and alloy films [17][19] have been reported, the publications on the utility of these films as strain gauges in devices such as pressure transducers are few.

In the present paper we report the study of a pressure transducer with Au-Ni $(89: 11)$ alloy thin-film strain gauges with a meandering path pattern [15].

The starting material for fabrication was $\mathrm{Au}-\mathrm{Ni}$ (82:18), a high-temperature brazing alloy with a unique characteristic, namely, its liquid and solid temperatures are the same $\left(950^{\circ} \mathrm{C}\right)$. Although this alloy is being used for brazing of stainless-steel foils, it is found to have very

Manuscript received March 13, 1992; revised June 3, 1992. This work was supported by ISRO, Department of Space, through the RESPOND program. The review of this paper was arranged by Associate Editor S. D. Senturia.

K. Rajanna and S. Mohan are with the Instrumentation and Services Unit, Indian Institute of Science, Bangalore 560012 , India.

M. M. Nayak, N. Gunasekaran, and A. E. Muthunayagam, are with the Pressure Transducer and Fabrication Facility, Liquid Propulsion Systems Centre, ISRO, Bangalore 560008 , India.

IEEE Log Number 9206465. good adhesion and corrosion resistance properties [20]. In view of these and since no study of this alloy with respect to strain gauges has been reported, an attempt to explore its suitability and applicability for thin-film strain gauge application has been made in the present work.

\section{EXPERIMENTATION}

In the present work an integrated diaphragm assembly has been employed. A special feature of this diaphragm design is the incorporation of a strain-relieving cavity to take care of the strain due to mechanical handling, mounting, or assembly process. The material used for the fabrication of the pressure transducer is precipitately hardened X17U4 steel. Further, details including the dimensions of the diaphragm assembly and the information on diaphragm surface preparation are given in our earlier publication [21]. Before depositing the sensing film (strain gauges), the insulating films consisting of alternate layers of $\mathrm{Al}_{2} \mathrm{O}_{3}$ and $\mathrm{SiO}_{2}$ were deposited on the diaphragm surface using reactive electron beam evaporation technique. The diaphragm assembly was maintained at $200^{\circ} \mathrm{C}$ during deposition. The need to deposit insulating oxide layers, the deposition process details, and the necessity to have multilayers instead of single-layer oxide films have already been described by Rajanna et al [21].

After the deposition of the insulating oxide layers, copper contact pad films and interconnecting copper pad films of thickness greater than $3000 \AA$ were deposited. Subsequently, Au-Ni film (strain gauge film) was deposited. The Au-Ni (82:18) material in the form of wire (obtained from Wilkinson Company, USA) was evaporated from a molybdenum boat. It is believed that since gold and nickel possess nearly the same vapor pressures at a given temperature, the possibility of fractionization of this alloy during evaporation is much smaller. In order to minimize the possibility of fractionization, a shutter was placed above the source during initial heating of the boat. The shutter was removed only when the boat temperature was sufficiently high to evaporate both the constituents of the alloy. The boat temperature during the evaporation was close to $1200^{\circ} \mathrm{C}$. The analysis of the deposited film by plasma emission spectrometry technique revealed the $\mathrm{Au}$ Ni composition as $89.2 \%: 10.8 \%$. This deviation in composition from starting material is attributed to the fact that single-source evaporation of a composite containing two or more components results in incongruent evaporation 


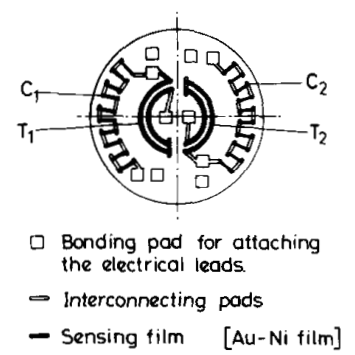

Fig. 1. Thin-film strain gauge pattern deposited on the pressure transducer diaphragm.

[22]. The thickness of the Au-Ni film (650 $\AA$ ) during deposition was measured and later compared using a multiple beam interferometer. Prior to deposition of copper and $\mathrm{Au}-\mathrm{Ni}$, the substrate was subjected to ionic cleaning for about $10 \mathrm{~min}$. Precision mechanical masks were used while depositing the above films of required pattern. These masks were prepared using a CNC (Computer Numerically Controlled) spark erosion machine with a dimensional tolerance of $\pm 1 \mu \mathrm{m}$. The strain-gauge pattern adopted (for the four gauges, as shown in Fig. 1) and their location on the diaphragm are the same as those already reported in our earlier paper [23].

The four gauges were connected in Wheatstone bridge configuration with all active gauges. The gauges experiencing the tensile strain (near the center) are connected in one set of opposite arms and those experiencing the compressive strain (at the diaphragm edge) in the other. It is important to note that the tensile strain causes the resistance of the gauge to increase and compressive strain results in decrease of resistance. The stabilization of the film was carried out by subjecting the diaphragm assembly to post-deposition heat treatment.

The output characteristics of the transducer were studied using a dead weight pressure calibrator (Model 5020 of Desgranges et Huot, France). The details of the procedure followed are given elsewhere [23].

\section{Results and Discussion}

\section{A. Effects of Post-Deposition Heat Treatment on the Thin-Film Strain Gauge System}

As can be seen in Table I, the post-deposition heat treatment resulted in a decrease in gauge resistance. The reduction in gauge resistance is attributed to annealing of defects incorporated in the film structure during deposition [24], [25]. It is important to note here that whereas the manganese film pressure transducer [23] had an average reduction of $6.5 \%$ in gauge resistance after heat treatment at $120^{\circ} \mathrm{C}$, the average reduction achieved in the present $\mathrm{Au}-\mathrm{Ni}$ film resistance was only $0.29 \%$. Therefore, in order to make sure of the almost complete annealing of defects, the heat treatment process was repeated at $170^{\circ} \mathrm{C}$. After the second heat treatment, the average decrease in gauge resistance was $1.36 \%$. However, further heat treatment did not result in any additional decrease in gauge resistance.
TABLE I

Resistance Values of Thin-Film Strain Gauges Deposited on the Pressure Transducer Diaphragm

\begin{tabular}{|c|c|c|c|}
\hline \multirow[b]{2}{*}{$\begin{array}{c}\text { Details of the } \\
\text { Thin-Film Strain } \\
\text { Gauges }\end{array}$} & \multicolumn{3}{|c|}{ Resistance Values $(\Omega)$} \\
\hline & $\begin{array}{c}\text { Before Heat } \\
\text { Treatment }\end{array}$ & $\begin{array}{l}\text { After Heat } \\
\text { Treatment } \\
\text { at } 120^{\circ} \mathrm{C} \\
\text { for } 1 \mathrm{~h}\end{array}$ & $\begin{array}{l}\text { After Second } \\
\text { Round of Heat } \\
\text { Treatment at } \\
170^{\circ} \mathrm{C} \text { for } 2 \mathrm{~h}\end{array}$ \\
\hline \multicolumn{4}{|c|}{ Gauges located at the edge of the diaphragm } \\
\hline gauge $C_{1}$ & 96.58 & 96.17 & 94.50 \\
\hline gauge $C_{2}$ & 99.59 & 99.31 & 98.23 \\
\hline \multicolumn{4}{|c|}{ Gauges located near the center of the diaphragm } \\
\hline gauge $T_{1}$ & 105.79 & 105.45 & 104.68 \\
\hline gauge $T_{2}$ & 104.92 & 104.78 & 104.00 \\
\hline
\end{tabular}

The insulation resistance of the oxide layers increased from about 300 to $40000 \mathrm{M} \Omega$ at $10 \mathrm{~V}$ dc due to postdeposition heat treatment. The increase in insulation resistance is believed to be due to enhanced oxidation of the individual oxide layers and the formation of stronger interfaces between layers.

\section{B. Individual Gauge Response}

Figs. 2 and 3 show the variation of relative change in resistance $\Delta R / R$ with pressure for the gauges $\left(T_{1}\right.$ and $\left.T_{2}\right)$ located near the center of the diaphragm and those at the edge $\left(C_{1}\right.$ and $\left.C_{2}\right)$ after the post-deposition heat treatment. It is observed that for all the gauges, the variation in $\Delta R / R$ with pressure is more linear and repeatable (between gauges) after the heat treatment process when compared to the variation of the same before the heat treatment.

\section{Output Performance of the Thin-Film Pressure Transducer}

The variation in output voltage of the pressure transducer as a function of input pressure is quite linear. The values of non-linearity and hysteresis (in percentage FSO; full scale output) versus pressure (in bars) are shown in Fig. 4. The maximum nonlinearity and hysteresis observed is $0.92 \%$ FSO. By considering the resistance of the thin-film strain gauges, the film thickness, the power dissipation factor, etc., the bridge excitation was optimized to $3 \mathrm{~V} \mathrm{dc}$. It has been observed that higher excitation voltages showed instability above $1 \%$ of FSO in the output of the pressure transducer under zero load condition. This instability at higher excitation voltages is considered to be due to excessive heating of the thin-film strain gauges.

Further, it was found that the nonlinearity and hysteresis improved after 1000 pressure cycles of a nominal pressure of 30 bar for 3-min duration carried out over a period of 8 months. The typical data of maximum nonlinearity and hysteresis observed after 500 cycles is $0.39 \%$ FSO. Again the maximum nonlinearity and hysteresis found after additional 500 cycles is $0.06 \%$ FSO. This indicates that films require about 1000 cycles to achieve nonlinearity and hysteresis of the order of $0.06 \%$, which 


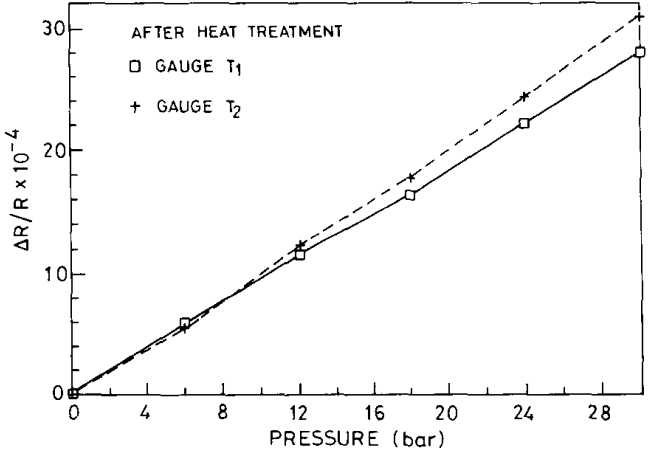

Fig. 2. Variation of relative change in resistance $\Delta R / R$ with pressure for gauges located near the center of the diaphragm-after heat treatment.

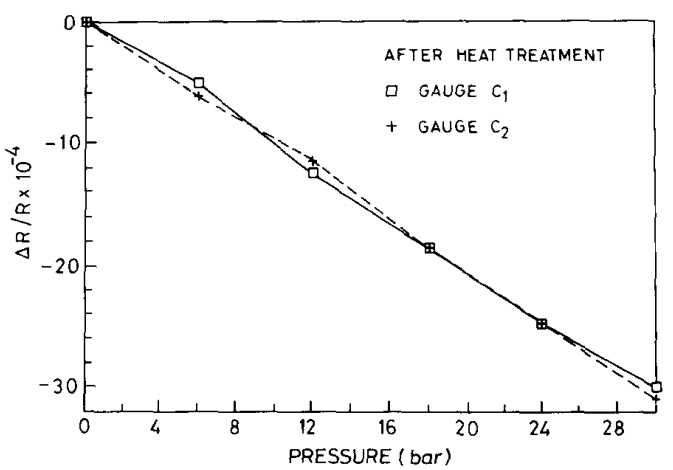

Fig. 3. Variation of relative change in resistance. $\Delta R / R$ with pressure for the gauges located at the edge of the diaphragm-after heat treatment.

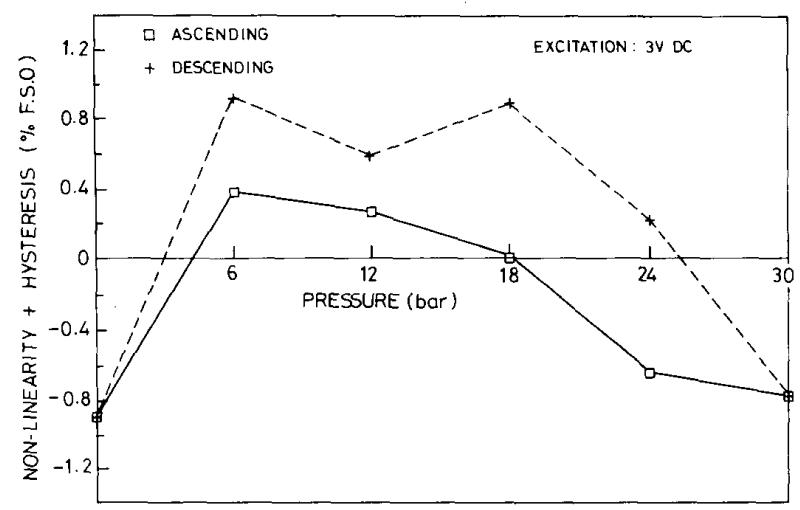

Fig. 4. Nonlinearity and hysteresis versus pressure.

is thought to be due to stress-relieving effects. Similar observation has been reported in the resistance-strain characteristics of metal films by Parker and Krinsky [1].

It has been observed that the FSO, zero-offset plots were linear and parallel with a negative slope of $0.111 \mathrm{mV} /{ }^{\circ} \mathrm{C}$. Also the net output was found to be linear in the temperature range $-20^{\circ} \mathrm{C}$ to $+70^{\circ} \mathrm{C}$ with a maximum deviation of less than $0.6 \%$.

In comparison with pressure transducer made with $\mathrm{Mn}$ film strain gauges [23], the present $\mathrm{Au}-\mathrm{Ni}$ film strain gauge transducer shows a stability of $0.6 \%$ in a time span of 4 months although the gauge resistance is lower and the film thickness is of the order of $650 \AA$. Also, it has been observed that the $\mathrm{Mn}$ film strain gauge transducer inevitably requires an overlayer to avoid atmospheric influence leading to change in resistance and hence output drift with time, whereas, $\mathrm{Au}-\mathrm{Ni}$ film pressure transducers do not require any overlayer.

\section{Conclusions}

The output performance of a thin-film pressure transducer with $\mathrm{Au}-\mathrm{Ni}$ film as the strain gauge has been studied with continuous excitation for at least $2 \mathrm{~h}$ before taking any output readings. It was found that the optimum bridge excitation was $3 \mathrm{~V} \mathrm{dc}$, since higher excitation voltages showed instability above $1 \%$ FSO which is thought to be due to excessive self-heating. The maximum nonlinearity and hysteresis observed after 1000 repeated pressure cycles over a period of 8 months was $0.06 \%$ FSO. The output behavior of the pressure transducer with temperature was also studied after stabilizing at each temperature for $2 \mathrm{~h}$ and it was found that the net output was linear with a maximum deviation of less than $0.6 \%$.

\section{ACKNOWLEDGMENT}

The authors wish to thank M. Ram for his involvement in the fabrication of precision masks. Thanks are also due to N. V. G. Nair and N. K. Ganesan for their assistance in carrying out the experimental work. The active participation of S. Srinivasulu during the discussion of the work reported in this paper is gratefully acknowledged.

\section{REFERENCES}

[1] R. L. Parker and A. Krinsky, "Electrical resistance-strain characteristics of thin evaporated metal films," J. Appl. Phys., vol. 34, pp. 2700-2708, 1963

[2] Z.H. Meiksin and R. A. Hudzinski, "A theoretical study of the effect of elastic strain on the electrical resistance of thin metal films," $J$. Appl. Phys., vol. 38, pp. 4490-4494, 1967.

[3] B. Hok, R. Nyholm, O. Groth, and P. A. Tove, "Study of discontinuous Au films with respect to strain gauge applications,"' Thin Solid Films, vol. 17, pp. 113-121, 1973.

[4] C. Reale, "Size effect on the electrical conductivity and longitudinal gauge factor of thin metal film," Czech. J. Phys., vol. B21, pp. 662672,1971

[5] S. Trapp, H. Fuchs, and H. Gleiter, "Generation of high sensitivity strain gauges by means of tunneling in discontinuous metallic films," Thin Solid Films, vol. 137, pp. L43-L46, 1986.

[6] M. R. Neuman and W. G. Sutton, "Structural dependence of strain gauge effect and surface resistivity if thin gold films," J. Vac. Sci. Technol., vol. 6, pp. 710-713, 1969.

[7] Z. H. Meiksin, E. J. Stolinski, H. B. Kuo, R. A. Mirchandani, and K. J. Shah, "A study of stable thin film pressure and strain transducer materials," Thin Solid Films, vol. 12, pp. 85-88, 1972.

[8] B. S. Verma and H. J. Juretschke, "Strain dependence of the resistivity of silver films," J. Appl. Phys., vol. 41, pp. 4732-4735, 1970

[9] B. S. Verma and G. C. Jain, "Size effect in longitudinal and transverse strain coefficient of resistance in silver films," Thin Solid Films. vol. 11, pp. 27-32, 1972.

[10] B. S. Verma, "Measurement of strain coefficient of resistance in si]ver films," Thin Solid Films, vol. 7, pp. 259-264, 1971.

[11] F. Warkusz, "Strain coefficient of resistance of thin copper films," Thin Solid Films, vol. 41, pp. 261-269, 1977. 
[12] G. R. Witt, "The electromechanical properties of thin films and the thin film strain gauge," Thin Solid Films, vol. 22, pp. 133-156, 1974.

[13] J. C. Anderson, "Thin film transducers and sensors," J. Vac. Sci. Technol., vol. 4, no. 3, pp. 610-616, May/June 1986.

[14] K. Rajanna and S. Mohan, "Longitudinal and transverse strain sensitivity of gold film," J. Mater. Sci. Lett., vol 6, pp. 1027-1029, 1987

[15] K. Rajanna and S. Mohan, "Studies on meandering path thin-film strain gauge,"'Sensors and Actuators, vol. 15, pp. 297-303, 1988.

[16] _ - "Strain-sensitive property of vacuum evaporated manganese films," Thin Solid Films, vol. 172, pp. 45-50, 1989.

[17] J. Gouault, S. Hubin, G. Richon, and B. Eudeline, "The electromechanical behaviour of a full component (dielectric and $\mathrm{Cu} / \mathrm{Ni}$ constantan alloy) for thin film strain gauge deposited upon steel substrate," Vacuum (GB), vol. 2, no. 4, pp. 363-365, 1977.

[18] G. Siddal and G. Smith, "A thin film resistor for measuring strain," Vacuum $(G B)$, vol. 9, pp. 144-146, 1960.

[19] S. Sampath and K. V. Ramanaiah, "Behavior of Bi-Sb alloy thin films as strain gauges,"' Thin Solid Films, vol. 137, pp. 199-205, 1986.

[20] The Wilkinson Company Catalogue on Precious Metals (published by Wilkinson Company, USA).

[21] K. Rajanna and S. Mohan, "Thin film pressure transducer with manganese film as the strain gauge," Sensors and Actuators $A$, vol. 24 , pp. 35-39, 1990.

[22] M. G. Krishna, G. K. Muralidhar, K. N. Rao, G. M. Rao, and S. Mohan, "A novel electron beam evaporation technique for the deposition of Superconducting thin films,"'Physica $C$, vol. 175, nos. 5, 6, pp. 623-626, 1991.

[23] M. M. Nayak, K. Rajanna, and S. Mohan, "Performance study of a pressure transducer with meandering path thin film strain gauges," Thin Solid Films, vol. 193/194, pp. 1023-1029, 1990.

[24] M. A. Angadi and P. V. Ashrit, "The effect of substrate temperature, deposition rate and annealing on the electrical resistivity of thin Yttrium films,"' J. Mat. Sci., vol. 18, pp. 3177-3182, 1983.

[25] V. V. Shah and Y. G. Naik, "Electrical properties of thin films of copper, silver and gold," Indian J. Pure Appl. Phys., vol. 3, pp. 2026, Jan. 1965.

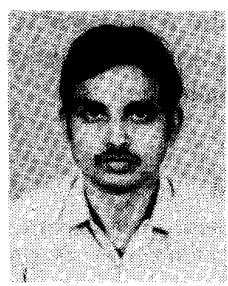

K. Rajanna graduated from the University of Mysore, India, with the B.Sc. degree in physics and mathematics in 1973 . He received the M.Sc degree in physics from the same university in 1976, and was awarded the M.Sc. (Engg.) degree from the Indian Institute of Science, Bangalore India in 1988 for his research work on thin-film strain gauges.

He started his career in the National Aeronautical Laboratory and later spent some time in the Reactor Research Centre (Department of Atomic Energy), Kalpakkam, before joining the Indian Institute of Science in 1983. At present he is a Senior Scientific Officer in the Instrumentation and Services Unit of the Indian Institute of Science. His current interest is in the area of thin-film transducers. Presently he is completing the requirements for the Ph.D. degree.

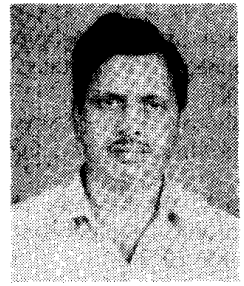

S. Mohan received the M.Sc. degree in physics from Sri Venkateswara University in 1967 and continued to work for the Ph.D. degree at the same university in the field of thin films

He was a member of the teaching faculty of the Physics Department at the Sri Venkateswara University during the period 1970-1977. He was selected as a National Associate by University Grants Commission in 1977 and worked for 3 months in the Thin Film Laboratory of the Indian Institute of Technology, New Delhi. He joined the Indian Institute of Science, Bangalore, in 1977 as a Senior Scientific Office and since 1988 has been an Associate Professor in the Instrumentation and Services Unit, in charge of the Vacuum and Thin Films group. In 1981 he was honored by Andhra Pradesh Academy of Sciences with a Young Scientist award. He was awarded the MRSI medal for 1992 by the Materials Research Society of India. His areas of interest include thin-film sensors, superconducting films, optical devices, and tribological coatings. He was the General Secretary of the Instrument Society of India during 1983-1989 and since 1989 has been the Convener, Thin Films group of the Materials Research Society of India. He has been the Editor of Journal of Instrument Society of India since 1991. He was a Visiting Professor for 3 months in 1990 at Forschung Zentrum, Julich, Germany. He has visited a number of countries to give lectures in reputed laboratories. He has published about 80 scientific publications in refereed journals and 6 review articles.

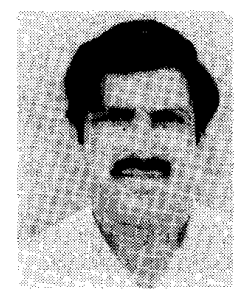

M. M. Nayak received the B.E. degree in elec trical engineering from Bangalore University, Bangalore, India, in 1982. Subsequently in 1984 he received the D.I.I.Sc. degree (a specialized post-graduate diploma in electronics design technology) from the Indian Institute of Science, Bangalore

He has undergone a one-year advanced training program at S.E.P. (Societe Europeenne de Propulsion), France, on space-qualified high-precision pressure transducers. In 1982 he was honored with an NRDC (National Research and Development Corporation of India) award for his developmental work on semiconductor pressure transducers. At present he is an engineer in charge of the developmental cell at the pressure transducer and fabrication facility, LPSC, of the Indian Space Research Organization. He is extensively involved in the development of thin film technologies for space applications which include pressure transducers, liquid level sensors and cryogenic sensors. He is working towards the Ph.D. degree.

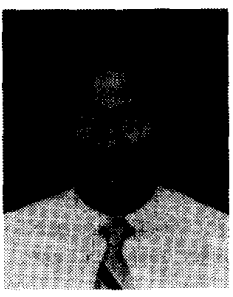

N. Gunasekaran received the degree in mechanical engineering from Madras University, Madras, India, in 1964

He has been with the Liquid Propulsion Systems Centre (LPSC) of ISRO for the last twenty years. He heads various groups engaged in the fabrication of hardware for rocket engines, liquid engines, development and batch production of transducers. At present he is the general manager of the Transducers and Light Alloy Fabrication Facility (TLF), LPSC. In recognition of his developmental work on semiconductor pressure transducers, he was honored with an NRDC award in 1982. His areas of interest include the design, development, and fabrication of various components for space application and precision transducers. Recently, he has also been involved in the design and development of cryogenic stages for GSLV (Geo-Stationary Launch Vehicles)

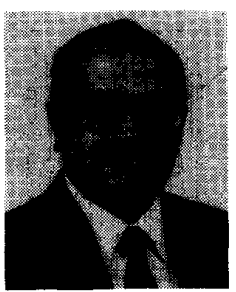

A. E. Muthunayagam was born in India on January 11,1939 . He received the B.E. degree in mechanical engineering in 1960 from the University of Madras, Madras, India, and the M.E. degree in power engineering from the Indian Institute of Science, Bangalore, India. In 1965, he received the Ph.D. degree from the School of Mechanical Engineering, Purdue University, West Lafayette, IN.

He joined the Indian Space Research Organization (ISRO) in 1966. As an outstanding propulsion engineer, he contributed significantly to the rocket propulsion technology development at ISRO. He is primarily responsible for the setting up of the Liquid Propulsion Systems Centre (LPSC) and streamlining its operation in building extensive test facilities for qualifying the space propulsion systems. His achievements also include development of second and fourth liquid stages for the PSLV, reaction control systems, and SITVC for launch vehicle projects such as SLV3, ASLV, and PSLV, monopropellant reaction control systems for IRS satellites, and liquid propulsion systems for INSAT-II project. He is the recipient of the Dr. V. M. Ghatage Award for the year 1989 from the Aeronautical Society of India. He is involved as a member of several Indian space programme projects/boards. $\mathrm{He}$ is also a member of the Space Propulsion Committee of the Interna tional Astronautical Federation, Paris, France. He is the Director, Liquid Propulsion Systems Centre (LPSC), ISRO and is also a member of ISRO Council. 